\title{
Peromyscus maniculatus (Rodentia: Cricetidae): An overlooked reservoir of tick-borne pathogens in the Midwest, USA?
}

\author{
Ryan T. Larson, ${ }^{1,2,3}$ Gebbiena M. Bron, ${ }^{1,4}$ XIA LeE, $^{1}$ Tela E. Zembsch, ${ }^{1,5}$ \\ PATRICIA N. SiY, ${ }^{1}$ AND SuSAN M. PASKEWITZ ${ }^{1, \dagger}$ \\ ${ }^{1}$ Department of Entomology, College of Agricultural and Life Sciences, University of Wisconsin-Madison, 1630 Linden Drive, Madison, \\ Wisconsin 53706 USA \\ ${ }^{2}$ Lieutenant Commander, Medical Service Corps, United States Navy, 7700 Arlington Blvd. Ste. 5113, Falls Church, \\ Virginia 22042-5113 USA \\ ${ }^{3}$ Naval Medical Leader \& Professional Development Command (NMLEPDC), 8955 Wood Road, Bethesda, Maryland 20889-5611 USA
}

Citation: Larson, R. T., G. M. Bron, X. Lee, T. E. Zembsch, P. N. Siy, and S. M. Paskewitz. 2021. Peromyscus maniculatus (Rodentia: Cricetidae): An overlooked reservoir of tick-borne pathogens in the Midwest, USA? Ecosphere 12(11):e03831. 10.1002/ecs2.3831

\begin{abstract}
Mice belonging to the genus Peromyscus are one of the most important reservoirs of tick-borne pathogens in the United States. However, the composition and abundance of Peromyscus species may vary geographically. The woodland deer mouse, Peromyscus maniculatus gracilis, is often abundant in the northern counties of Minnesota, Wisconsin, and Michigan. In these states, multiple pathogens transmitted by the blacklegged tick, Ixodes scapularis, are endemic. In comparison to the well-studied white-footed mouse, Peromyscus leucopus, little is known about the importance of P. maniculatus in maintaining natural cycles of tick-borne pathogens. We conducted small mammal trapping in north-central Wisconsin and compared the modified reservoir potential of $P$. maniculatus to P. leucopus. Based on mixed-model regression analysis, individual P. maniculatus were 2.07 (1.07-4.01) times more likely to be infected with Borrelia burgdorferi compared with P. leucopus. We report the first detection of three emerging tick-borne pathogens (Babesia microti, Borrelia mayonii, and Ehrlichia muris eauclairensis) in P. maniculatus. Additionally, P. maniculatus infected with Ba. microti were 4.8 (2.74-8.50) times more likely to be concurrently infected with Bo. burgdorferi compared with P. leucopus. While we found individual P. leucopus to be more infested with both larval and nymphal I. scapularis, P. maniculatus was the more abundant species. As a result, P. maniculatus had a higher modified reservoir potential in our study area and was likely responsible for feeding and infecting more ticks with pathogens than P. leucopus. Overall, our results illustrate that $P$. maniculatus is an important reservoir in areas of the Midwest, where it occurs in high abundance.
\end{abstract}

Key words: Babesia microti; Borrelia burgdorferi; coinfection; Lyme disease; Peromyscus leucopus.

Received 1 March 2021; revised 25 June 2021; accepted 12 July 2021. Corresponding Editor: Andrea Swei.

Copyright: (C) 2021 The Authors. Ecosphere published by Wiley Periodicals LLC on behalf of Ecological Society of America. This article has been contributed to by US Government employees and their work is in the public domain in the USA. This is an open access article under the terms of the Creative Commons Attribution License, which permits use, distribution and reproduction in any medium, provided the original work is properly cited.

${ }^{4}$ Present address: Animal Sciences Group, Quantitative Veterinary Epidemiology, Wageningen University \& Research, Droevendaalsesteeg 1 Wageningen 6708 PB The Netherlands.

${ }^{5}$ Present address: New York State Department of Health, Bureau of Communicable Disease Control, Albany, New York 12237 USA.

$\dagger$ E-mail: smpaskew@wisc.edu 


\section{INTRODUCTION}

The Midwest, USA, is a hotspot for emerging and endemic tick-borne pathogens transmitted through the bite of the blacklegged tick, Ixodes scapularis Say (Eisen et al. 2017). The white-footed mouse, Peromyscus leucopus Rafinesque, occurs throughout much of the Midwest (Long 1996, Jannett et al. 2007, Myers et al. 2009) and is considered an important host for immature I. scapularis as well as a reservoir for multiple tick-borne pathogens including Anaplasma phagocytophilum, Babesia microti, Borrelia burgdorferi, Bo. mayonii, Bo. miyamotoi, Ehrlichia muris eauclairensis, and Powassan virus (Ruebush et al. 1981, Levine et al. 1985, Telford et al. 1996, Scoles et al. 2001, Johnson et al. 2011, 2017, Castillo et al. 2015, Barbour 2017). However, the abundance of $P$. leucopus varies geographically and the woodland deer mouse, Peromyscus maniculatus gracilis Wagner, is also common in the northernmost counties of Minnesota, Wisconsin, and Michigan where the two mice occupy similar habitats (Long 1996, Myers et al. 2009, Stephens and Anderson 2014). Here, we assessed the importance of each of these Peromyscus species as tick-borne pathogen reservoirs at a field site in the Midwest.

While $P$. maniculatus is known to serve as a host to immature I. scapularis and play a role in maintaining natural cycles of Bo. burgdorferi (Rand et al. 1993), their importance as a reservoir of tick-borne pathogens is not well understood. Peromyscus leucopus and P. maniculatus were found to have similar Bo. burgdorferi infection rates when compared directly in field studies (Friedrich 2003, Simon et al. 2014, Larson et al. 2018). The two species also showed comparable susceptibility to $B o$. burgdorferi when intravenously inoculated with spirochetes in a laboratory experiment (Burgess et al. 1986). By contrast, $P$. maniculatus was found to have a higher prevalence of $A$. phagocytophilum (Larson et al. 2018), which suggests that the two species might not be equally susceptible to all pathogens. Of the tick-borne pathogens that are known to occur in the Midwest and cause human disease, only A. phagocytophilum, Bo. burgdorferi, Bo. miyamotoi, and Powassan virus have been reported from field-caught $P$. maniculatus (Rand et al. 1993, Deardorff et al. 2013, Larson et al. 2018, Sambado et al. 2020).

ECOSPHERE *www.esajournals.org
In addition to the host pathogen prevalence, host densities and tick infestations rates are also important factors in estimating the number of ticks infected by a given host species (Mather et al. 1989, Hamer et al. 2012). Immature I. scapularis infestations on P. leucopus and P. maniculatus were compared in allopatric populations in Maine (Rand et al. 1993) and sympatric populations in Michigan (Friedrich 2003), Wisconsin (Larson et al. 2018), and Quebec (Bouchard et al. 2011). With the exception of the study in Quebec, $P$. leucopus was more frequently infested with larval $I$. scapularis and at higher intensity than $P$. maniculatus. In contrast, differences in nymphal infestation between P. maniculatus and P. leucopus were less consistent across previous studies (Rand et al. 1993, Friedrich 2003, Bouchard et al. 2011, Larson et al. 2018). While P. leucopus appears to have a higher propensity for being infested with larval I. scapularis, the relative abundance of each host species could vary. Therefore, despite being associated with lower tick infestations, $P$. maniculatus could potentially feed and infect more ticks in areas where it occurs in higher abundance.

It has been suggested that the distribution and relative abundances of these Peromyscus spp. are linked to climate and that warming temperatures in the Midwest are favoring P. leucopus (Long 1996, Myers et al. 2005, 2009). The relative abundances of these mouse species are known to fluctuate in response to temperature and resource availability with $P$. maniculatus being more adapted to cold weather and P. leucopus a more prolific breeder (Drickamer and Vestal 1973, Long 1996, Wolff 1996, Myers et al. 2005). RoyDufresne et al. (2013) found the current distribution of P. leucopus in Quebec to be highly correlated with winter length and winter temperatures in that the probability of occurrence increased with milder winters. Moreover, longterm observations suggest that warming temperatures are responsible for $P$. leucopus replacing $P$. maniculatus on Michigan's Lower Peninsula (Myers et al. 2005, 2009). Therefore, understanding differences in pathogen prevalence and tick infestations between these species is a timely topic that may provide some insights on how warming temperature may affect tick-borne disease risk in the Midwest. Based on its propensity to have higher infestations with larval I. scapularis 
(Larson et al. 2018), we expect P. leucopus to be feeding and infecting more larval ticks with tickborne pathogens.

To further elucidate the importance of $P$. maniculatus as a reservoir of tick-borne pathogens in the Midwest, we compared the modified reservoir potential by assessing tick infestations, abundance, and pathogen prevalence of $P$. maniculatus to the more extensively studied $P$. leucopus. We tested individual mice for A. phagocytophilum, Bo. burgdorferi, and Bo. miyamotoi as well as Ba. microti, Bo. mayonii, and E. muris eauclairensis which have not been previously reported as infecting $P$. maniculatus (Barbour 2017). Previous studies examining $P$. leucopus have found that concurrent infection with Bo. burgdorferi and $B a$. microti were higher than expected and that $B a$. microti infection preceded Bo. burgdorferi (Hersh et al. 2014, Tufts and Diuk-Wasser 2018). Therefore, we examined the coinfection status of all mice.

\section{Materials ANd Methods}

\section{Small mammal trapping and sample collection}

Small mammals were live-trapped at 10 hardwood forest sites within the ChequamegonNicolet National Forest located in Taylor County, WI, where both $P$. leucopus and P. maniculatus are known to occur (Long 1996). This is the same county in which the first known case of erythema migrans, the hallmark symptom of Lyme disease, was reported (Scrimenti 1970). Fig. 1 displays the approximate range of $P$. maniculatus based on occurrence records obtained from the Global Biodiversity Information Facility (GBIF) database as well as the study site location (Peromyscus maniculatus subsp. gracilis GBIF Secretariat 2017). Trapping was conducted from June to August in 2018 and 2019. All trapping was conducted in accordance with Institutional Animal Care and Use Committee protocol (AA005400) approved by University of Wisconsin-Madison. Trapping grids of at least 0.5 ha were established with 12.5 $\mathrm{m}$ or $15 \mathrm{~m}$ trap spacing and 60 to 81 traps at each site. Sherman traps, $28 \times 9 \times 23 \mathrm{~cm}$ (H.B. Sherman Inc., Tallahassee, Florida, USA) and Heslinga live traps (Heslinga traps, Groningen, The Netherlands), were baited before sunset and checked in the morning of the following day. Grids were pre-baited for one night and trapped for two to four nights per month. Captured animals were sexed, ear-tagged, weighed, examined for ticks, and ear biopsies and blood samples were collected. Mice were classified as immature or adult based on their mass; mice which had a mass of $16 \mathrm{~g}$ or more were classified as adults and mice $<16 \mathrm{~g}$ as juveniles (Larson et al. 2018). Ear punch biopsies were collected using a two-mm (Integra Miltex, York, Pennsylvania, USA) disposable biopsy punch and placed in $70 \%$ ethanol. Blood was collected via tail vein sampling and stored on filter paper (Whatman 903 Multipart Neonatal Protein Saver Cards, Pittsburgh, Pennsylvania, USA) at $4^{\circ} \mathrm{C}$. Ticks were placed in vials containing $70 \%$ ethanol and stored at room temperature until identification. All ticks were identified to life stage and species according to established taxonomic keys (Clifford et al. 1961, Durden and Keirans 1996).

\section{DNA extraction tissue and blood}

Ear punch biopsy samples.-A sterile 18-gauge needle (Becton, Dickinson and Company, Franklin Lakes, New Jersey, USA) was used to bisect each ear biopsy. We used the ISOLATE II Genomic DNA Kit (Meridian Life Sciences, Memphis, Tennessee, USA) in accordance with the manufacturer's protocol to isolate DNA from bisected biopsies. Extracted DNA was eluted to a total volume of $75 \mu \mathrm{L}$.

Blood samples.-The adjusted methods of Bereczky et al. (2005) previously reported in Larson et al. (2018) were used to extract DNA from blood cards. Briefly, a six mL sample of each blood card was removed using a disposable biopsy punch (Integra Miltex). Erythrocytes were lysed by incubating blood punches in $1 \mathrm{~mL}$ of a $0.5 \%$ saponin solution at $4^{\circ} \mathrm{C}$ overnight. Following incubation, the saponin solution was removed and replaced with one $\mathrm{mL}$ of a $1 \mathrm{X}$ PBS solution for $30 \mathrm{~min}$ at $4^{\circ} \mathrm{C}$. Filter paper punches were transferred to new preheated tubes containing $50 \mu \mathrm{L}$ of $20 \%$ Chelex-100 (20 mg/80 mL) in 1X PBS solution and $150 \mu \mathrm{L}$ of distilled water and incubated for $10 \mathrm{~min}$ at $100^{\circ} \mathrm{C}$. Tubes were then centrifuged at $10,000 \mathrm{~g}$ for two minutes before the supernatant was transferred to a new tube and centrifuged for an additional two minutes at 10,000 g. Finally, the resulting supernatant was transferred to a new tube and stored at $-20^{\circ} \mathrm{C}$ until Peromyscus spp. identification and pathogen testing was performed. 


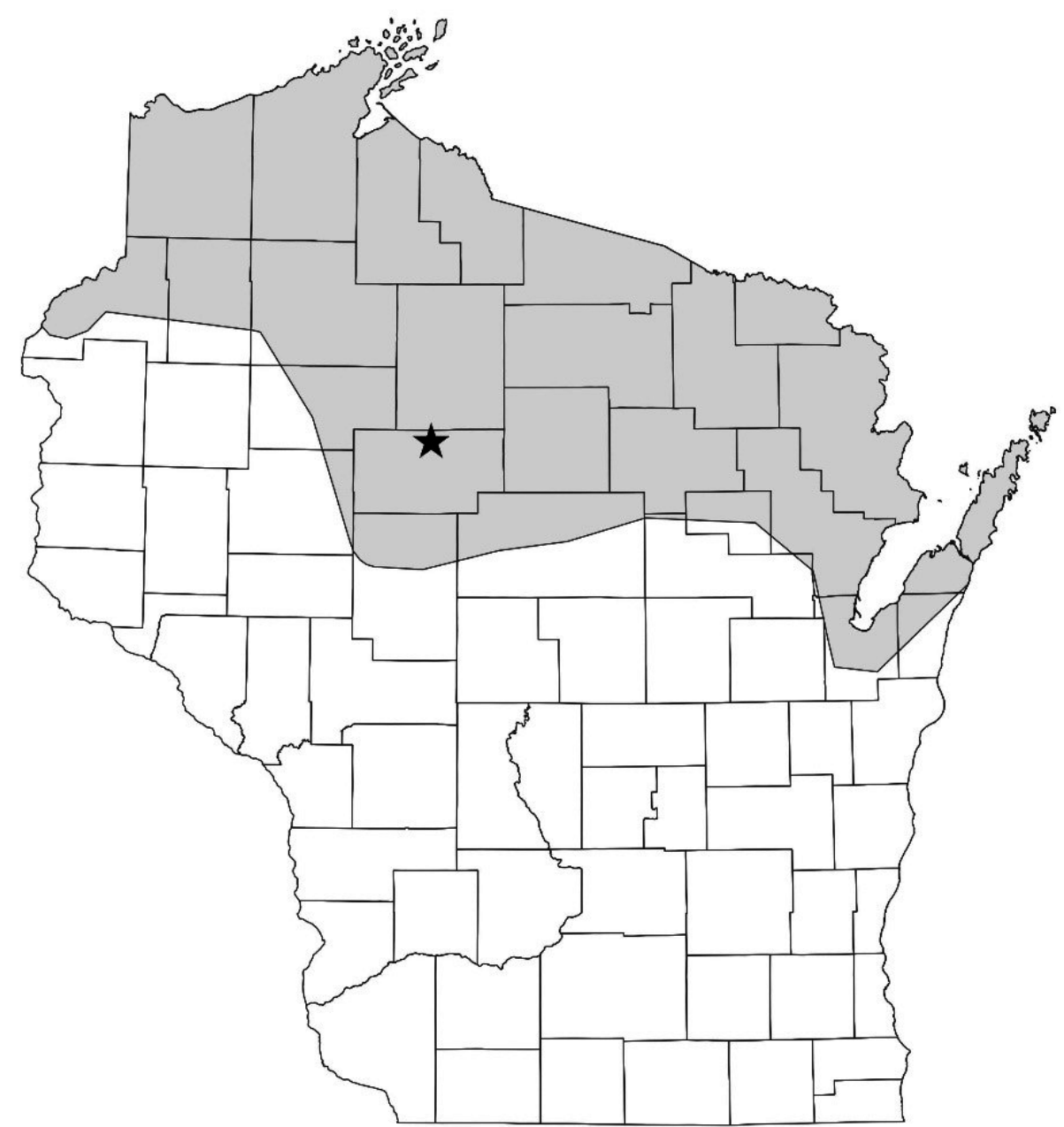

Fig. 1. Approximate range of Peromyscus maniculatus gracilis, indicated by the shaded gray area, in Wisconsin (P. maniculatus subsp. gracilis in GBIF Secretariat 2017). Peromyscus leucopus occurs throughout the state of Wisconsin. The star indicates our study site at the Chequamegon Nicolet National Forest located in Taylor County, WI.

\section{PCR identification of Peromyscus spp.}

Peromyscus maniculatus and P. leucopus were differentiated using multiplex primers targeting COIII in polymerase chain reactions (PCR) as described by Tessier et al. (2004). We separated PCR products on a $2 \%$ agarose gel stained with Gel Red (Biotium, Inc., Fremont, California, USA) and visualized under UV light.

\section{Pathogen detection}

For pathogen detection, we modified the methods of Babady et al. (2008) and Stauffer et al. (2020), which use quantitative PCR based on fluorescent resonance energy transfer probes. We used DNA extracted from ear tissue biopsies for detection of Bo. burgdorferi and Bo. mayonii, while DNA extracted from blood cards was used for detecting A. phagocytophilum, Bo. miyamotoi, E. m. eauclairensis, and Ba. microti. Primer, probes, melting temperatures, and limits of detection for each pathogen can be found in Appendix S1: Table S1. Briefly, reactions of $20 \mu \mathrm{L}$ were prepared by adding five $\mu \mathrm{L}$ of DNA eluate to 15 $\mu \mathrm{L}$ of $1 \times$ LightCycler FastStart DNA Master HyProbe (Roche, Indianapolis, Indiana, USA), magnesium chloride, primers, and probes (Appendix S1: Table S1). All reactions were run using a LightCycler 2.0 instrument (Roche) 
following the cycling conditions as described in Babady et al. (2008). Constructed plasmids (TIB Molbiol, LLC, Adelphia, New Jersey, USA) diluted in PCR grade water served as the positive controls, and five $\mu \mathrm{L}$ of PCR grade water served as negative control. Limits of detection for each pathogen were established by running standard curves in triplicate. For each standard curve, plasmids were diluted in PCR grade water ranging from $10^{7}$ to $10^{-2}$ copies $/ \mu \mathrm{L}$.

\section{Statistical analysis}

All data analyses and modeling were conducted in R 3.4.4 ( $\mathrm{R}$ Development Core Team 2018). For each pathogen tested, prevalence was calculated by dividing the number of positive animals by the total number of individuals tested. We determined the mean intensity of tick infestations by calculating the average tick infestations of mice that were infested with at least one tick.

Modeling tick abundance.-Captures with missing variables were removed from the data set. We fit generalized linear mixed models (GLMM) from package lme4 (Bates et al. 2015) to assess tick abundance. We hypothesized that tick abundance on a mouse could be due to characteristics of the mouse (species, sex, and age) as well as the sample month, year, and site. We estimated the abundance of larval I. scapularis on individual mice by fitting a GLMM with a negative binomial distribution using the function "glmer.nb." For negative binomial models, we used a bound optimization by quadratic approximation optimizer and 100,000 iterations to improve model convergence. Tick abundance was based on the first time an individual animal was captured each month. Fixed effects in our full model included species (P. leucopus or P. maniculatus), age (adult or juvenile), sex (male or female), month (June, July, or August), and year (2018 or 2019). Site was used as a random effect in our models to account for potential effects of spatial autocorrelation on tick abundance (Cayol et al. 2018). We fit a full model including species, sex, age, month, and year as a starting point for model comparison. As an alternative to manually fitting models, we used the "dredge" function from the MuMIn package (Barton 2019) to assess all possible model combinations ranked by small-sample corrected Akaike information criterion $\left(\mathrm{AIC}_{\mathrm{c}}\right)$. In lieu of using model selection to identify a singular best model, we employed multimodel inference to consider information from all competing models (Burnham and Anderson 2002, Kaizer et al. 2015). Following VanAcker et al. (2019), all models within two $\mathrm{AIC}_{\mathrm{c}}$ of the best fit model were considered competitive and were selected for model averaging. We used conditional model averaging, which only uses estimates of parameters if they appeared in models and does not substitute parameter estimates with zero in cases where they did not appear in models (full model averaging). Model averaging was conducted using the "model.avg" function, which is also available through the MuMIn package (Barton 2019). Finally, we displayed the average prediction of all models with $\Delta \mathrm{AIC}_{\mathrm{c}}<2$.

Modeling infection prevalence.-We repeated the same approach for modeling Bo. burgdorferi infection and added concurrent infection with $B a$. microti as a variable, because this has been shown to be associated with Bo. burgdorferi in mice (Dunn et al. 2014, Hersh et al. 2014). We modeled the probability of individual mice being infected with Bo. burgdorferi, the most commonly detected pathogen, upon first capture by fitting a logistic regression with random effects using the function "glmer." Fixed effects of the pathogen prevalence model included host characteristics (age, sex, year, and concurrent infection with $\mathrm{Ba}$. microti) and sampling time (month and year). Site was included as a random effect. We exponentiated model estimates to obtain adjusted odds ratios (AOR), which displays how a one unit increase in explanatory variable changes the ratio of individual mice being infected.

Assessing temporal patterns of coinfection.-We assessed temporal patterns of pathogen coinfections for mice that were captured in at least two separate months and concurrently tested positive for Ba. microti and Bo. burgdorferi within at least one of the months captured. These patterns were displayed using the "geom_tile" function in the ggplot2 package (Wickham 2016).

Host density estimation.-Detailed methods describing our host density estimation can be found in Appendix S2. Briefly, to estimate host density, we modeled mouse abundance and estimated the effective area trapped. Peromyscus leucopus and $P$. maniculatus abundance were 

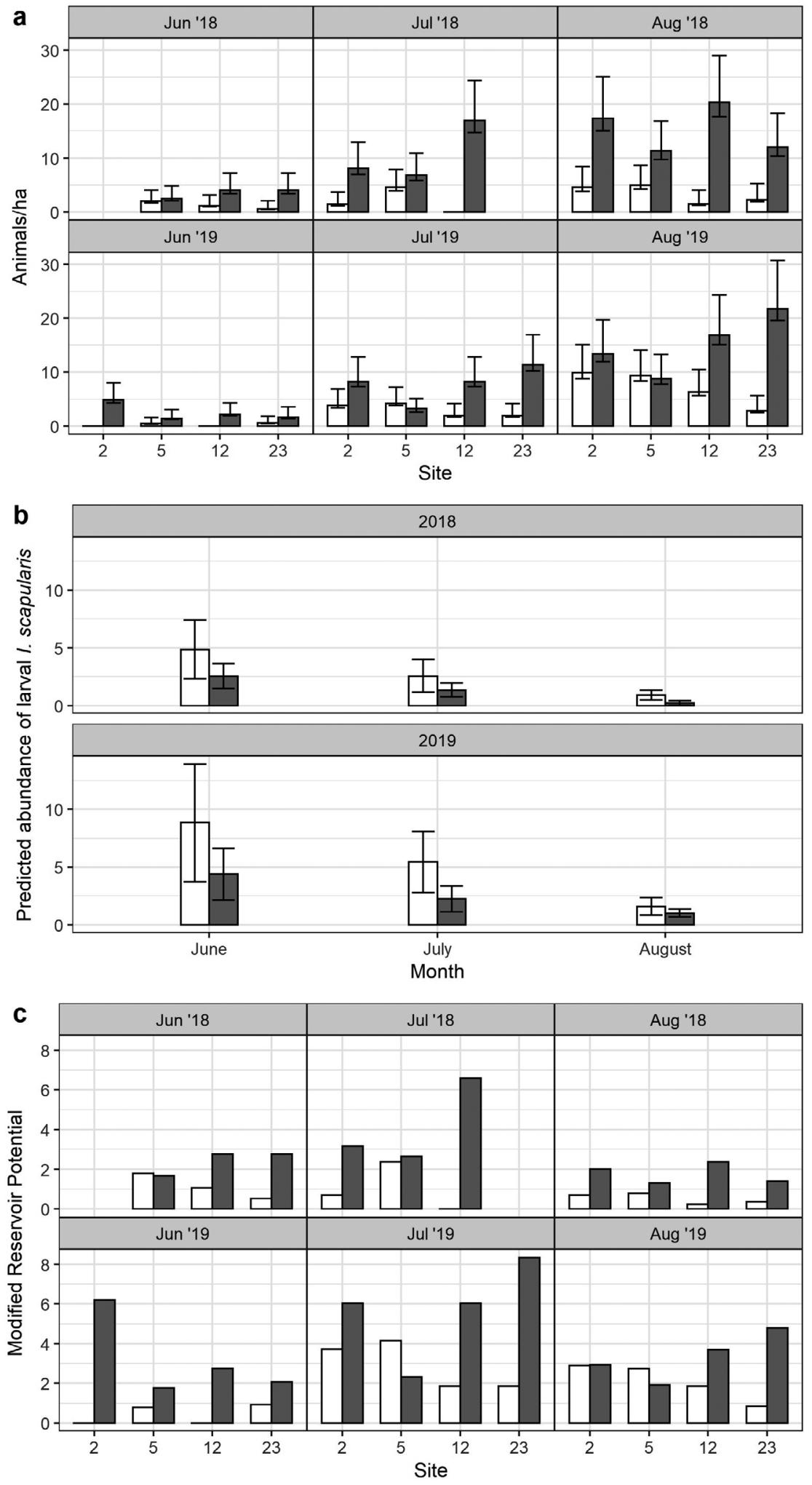

Fig. 2. (a) Estimated host density (error bars represent $95 \%$ confidence intervals), (b) predicted abundance of 
(Fig. 2. Continued)

larval Ixodes scapularis infestations (error bars represent 95\% confidence intervals), and (c) monthly modified reservoir potential of Peromyscus leucopus (white bars) and Peromyscus maniculatus (grey bars). Modified reservoir potential is an estimate of the number of larval I. scapularis that each host species is responsible for infecting with Borrelia burgdorferi.

estimated for four sites that were sampled in both years with Huggins robust design models using RMark (Huggins 1989, Laake 2013). Abundances $(N)$ were grouped by species $(n=2)$, trap session $(n=6)$, and site $(n=4)$. To convert $N$ to densities, we estimated the effective trapping area for each species, trap session, and site, by adding a buffer strip equal to one half the mean maximum distance moved (MMDM) of mice to the trapping grid area (Parmenter et al. 2003, Schwemm et al. 2018). Maximum distance moved was defined as the distance between the two farthest traps used by an individual mouse within monthly trapping sessions. Densities were obtained by dividing $N$ by the effective trapping area.

Comparing modified reservoir potential.-For each species, we calculated the modified reservoir potential as described by Hamer et al. (2012), which was an estimate of the number of ticks that feed on Bo. burgdorferi-infected hosts of a certain species. Modified reservoir potential was obtained by the product of density of ticks expected to be fed by a given host species (feeding density) and the proportion of a given host species that was infected with Bo. burgdorferi. We compared monthly modified reservoir potential at four sites in which we were able to estimate densities across years and months. Monthly feeding density was obtained for each species by multiplying model-averaged predictions of larval infestations (see Modeling tick abundance) and the estimated host density for each year, month, and site. The proportion of a given host species that was infected with Bo. burgdorferi was estimated from the species-specific Bo. burgdorferi prevalence across all months, years, and sites. For each month and site in which both species were present, we compared the difference in modified reservoir potential between species using a paired $t$-test.

\section{RESULTS}

Throughout 7,877 trap nights, we captured 438 unique Peromyscus spp. individuals 1041 times in total, and 549 times when considering the first time an animal was captured each month. Twenty-four of the 549 monthly captures (representing 15 individuals) were removed from analysis due to missing information. After removing incomplete observations, the data used for our tick abundance and pathogen prevalence models included 423 individual Peromyscus (97 P. leucopus and 326 P. maniculatus), which were captured 525 times (120 P. leucopus and 405 P. maniculatus).

\section{Host density estimation}

Modeling results for host abundance estimates and effective area trapped are contained in Appendix S2. Peromyscus maniculatus densities were higher than $P$. leucopus across all sites, years, and months (Fig. 2a). Site 2 was not trapped in June 2018, and site 23 was removed from density estimation analysis in July 2018 due to a heavy rainfall event, which prevented the processing of animals captured during the third trapping night. Mouse densities increased throughout the summer and were highest in August (Fig. 2a).

\section{Tick infestations}

We collected 986 larval and 56 nymphal $I$. scapularis from 296 mice. The overall prevalence of larval I. scapularis infestation for P. leucopus and P. maniculatus was $71 \%(85 / 120)$ and $50 \%$ (204/405), respectively (Table 1$)$. Overall mean intensities of infestation with larval I. scapularis for P. leucopus and P. maniculatus were 3.94 (median $=3$; range $=1,18)$ and $3.19(2 ; 1,26)$, respectively (Table 2 ). During each trapping session, $P$. leucopus had a higher prevalence of both larval and nymphal ticks (Table 1). With the exception of the August trapping session in 2019, P. leucopus was also found to have higher mean intensities of infestation with larval I. scapularis (Table 2). We also collected a total of 247 immature Dermacentor variabilis Say (229 larvae and 18 nymphs) from 94 individual mice. The prevalence of infestation of immature $D$. variabilis on $P$. leucopus and P. maniculatus was 23\% (27/120) and 
Table 1. Prevalence of infestation with Ixodes scapularis by trapping session.

\begin{tabular}{|c|c|c|c|c|c|}
\hline Year & Life stage & Species & June & July & August \\
\hline \multirow[t]{4}{*}{2018} & \multirow[t]{2}{*}{ Larvae } & Peromyscus leucopus & $88 \%(7 / 8)$ & $75 \%(12 / 16)$ & $42 \%(8 / 19)$ \\
\hline & & Peromyscus maniculatus & $80 \%(33 / 41)$ & $58 \%(40 / 69)$ & $19 \%(15 / 80)$ \\
\hline & \multirow[t]{2}{*}{ Nymphs } & Peromyscus leucopus & $25 \%(2 / 8)$ & $0 \%(0 / 16)$ & $5 \%(1 / 19)$ \\
\hline & & Peromyscus maniculatus & $17 \%(7 / 41)$ & $0 \%(0 / 69)$ & $1 \%(1 / 79)$ \\
\hline \multirow[t]{4}{*}{2019} & \multirow[t]{2}{*}{ Larvae } & Peromyscus leucopus & $100 \%(2 / 2)$ & $95 \%(19 / 20)$ & $67 \%(37 / 55)$ \\
\hline & & Peromyscus maniculatus & $72 \%(13 / 18)$ & $79 \%(52 / 66)$ & $39 \%(51 / 131)$ \\
\hline & \multirow[t]{2}{*}{ Nymphs } & Peromyscus leucopus & $100 \%(2 / 2)$ & $35 \%(7 / 20)$ & $5 \%(3 / 55)$ \\
\hline & & Peromyscus maniculatus & $28 \%(5 / 18)$ & $12 \%(8 / 66)$ & $5 \%(6 / 131)$ \\
\hline
\end{tabular}

Table 2. Mean intensity (median, range) of infestation with Ixodes scapularis by trapping session.

\begin{tabular}{|c|c|c|c|c|c|}
\hline Year & Life stage & Species & June & July & August \\
\hline \multirow[t]{4}{*}{2018} & \multirow[t]{2}{*}{ Larvae } & Peromyscus leucopus & $10.1(10,5-18)$ & $3.83(3.5,1-8)$ & $1.75(1,1-4)$ \\
\hline & & Peromyscus maniculatus & $5(4,1-14)$ & $2.33(1,1-15)$ & $1.53(1,1-4)$ \\
\hline & \multirow[t]{2}{*}{ Nymphs } & Peromyscus leucopus & $1.5(1.5,1-2)$ & N/A & $1(1,1-1)$ \\
\hline & & Peromyscus maniculatus & $1(1,1-3)$ & N/A & $1(1,1-1)$ \\
\hline \multirow[t]{4}{*}{2019} & \multirow[t]{2}{*}{ Larvae } & Peromyscus leucopus & $5.5(5.5,3-8)$ & $5.68(5,1-15)$ & $2.30(1,1-6)$ \\
\hline & & Peromyscus maniculatus & $2.31(2,1-7)$ & $3.56(2,1-26)$ & $3.04(2,1-16)$ \\
\hline & \multirow[t]{2}{*}{ Nymphs } & Peromyscus leucopus & $1(1,1-1)$ & $1.29(1,1-2)$ & $1(1,1-1)$ \\
\hline & & Peromyscus maniculatus & $1.4(1,1-3)$ & $1.75(1,1-4)$ & $1.17(1,1-2)$ \\
\hline
\end{tabular}

$17 \%$ (67/405), respectively. The overall mean intensities of infestation with immature $D$. variabilis on $P$. leucopus and $P$. maniculatus were 2.6 $($ median $=2$; range $=1,36)$ and $2.6(2 ; 1,11)$, respectively.

\section{Modeling tick abundance}

The two selected models describing larval $I$. scapularis abundance on mice both included month, species, and year as covariates (Appendix S3: Table S1). Larval I. scapularis infesting mice was highest in June and decreased throughout the summer (Fig. 2b. and Table 3). Additionally, larval I. scapularis abundance in 2019 was 1.88 times higher than in 2018 (Fig. 2b and Table 3). Larval abundance on P. maniculatus was 0.47 times lower than on $P$. leucopus (IRR = $0.47,95 \%$ C.I. $0.36-0.63, P<0.001)$. We found no evidence of an association between either mouse age or sex on larval I. scapularis abundance.

\section{Pathogen prevalence}

In P. maniculatus, we detected all six pathogens: Ba. microti, Bo. burgdorferi, Bo. mayonii, Bo.

Table 3. Conditional average for two models describing the abundance of infestation of larval Ixodes scapularis.

\begin{tabular}{|c|c|c|c|c|c|}
\hline \multirow[b]{2}{*}{ Fixed Effect } & \multirow[b]{2}{*}{ Level } & \multicolumn{3}{|c|}{ Larval Ixodes scapularis abundance } & \multirow[b]{2}{*}{$\operatorname{IRR}(95 \% \mathrm{CI})$} \\
\hline & & Coefficient (SE) & Z & $P$ & \\
\hline & (Intercept) & $1.59(0.27)$ & 6.0 & $<2 \mathrm{e}-16^{* * *}$ & $4.87(2.89-8.20)$ \\
\hline Age & Immature & $-0.07(0.14)$ & 0.49 & 0.63 & $0.93(0.71-1.23)$ \\
\hline \multirow[t]{2}{*}{ Month } & July & $-0.56(0.21)$ & 2.73 & $0.0064^{* *}$ & $0.57(0.38-0.85)$ \\
\hline & August & $-1.77(0.21)$ & 8.44 & $<2 \mathrm{e}-16^{* * *}$ & $0.17(0.11-0.26)$ \\
\hline Species & P. maniculatus & $-0.75(0.14)$ & 5.26 & $1.0 \mathrm{e}-07^{* * *}$ & $0.47(0.36-0.63)$ \\
\hline Year & 2019 & $0.63(0.14)$ & 4.50 & $6.9 \mathrm{e}-06^{* * *}$ & $1.88(1.43-2.48)$ \\
\hline
\end{tabular}

Notes: Fixed effects included: Month $=$ month trapped (two levels, June is the reference). Species = Peromyscus species (two levels, $P$. leucopus is the reference). Year = year sampled (two levels, 2018 is the reference). Age = age of mouse (two levels, adult is the reference). Random effect included site. Number of models refers to the subset of models with $\mathrm{AIC}_{\mathrm{c}}<2$. Number of observations $=525$. IRR, incidence rate ratio. ${ }^{* *}$ means parameter significantly affected the abundance of larvae on mice at $P<0.01$ level. ${ }^{* * *}$ means the parameter significantly affected the abundance of larvae on mice at $P<0.001$ level. 
miyamotoi, A. phagocytophilum, and E. m. eauclairensis. Borrelia mayonii and E. m. eauclairensis were not detected in samples collected from $P$. leucopus (Table 4). At first capture, Bo. burgdorferi prevalence in $P$. leucopus and $P$. maniculatus was $19 \%(18 / 94)$ and $30 \%(94 / 318)$, respectively. The prevalence of Ba. microti in P. leucopus and P. maniculatus was 15\% (14/94) and 25\% (80/318), respectively. Prevalence of Bo. burgdorferi and Ba. microti coinfection was 9\% (8/94) in P. leucopus and $16 \%$ (51/318) in P. maniculatus (Table 4). While we detected coinfections involving other pathogens, we had too few to analyze.

Peromyscus maniculatus were 2.06 times more likely to be infected with Bo. burgdorferi in comparison to $P$. leucopus (95\%CI: 1.07-3.98, $P=0.03$ ) (Table 5). Mice infected with $B a$. microti were 4.78 times more likely to be concurrently infected with Bo. burgdorferi (95\%CI: 2.70-8.34, $P<0.001$ ). Juvenile mice were less likely to be infected with Bo. burgdorferi compared to adult mice (AOR = 0.06, 95\% CI: 0.02-0.18, $P<0.001)$. No associations between Bo. burgdorferi infection status and sex, month, or year were found (Appendix S3: Table S2).

Table 4. Pathogen prevalence at first capture.

\begin{tabular}{lcccc}
\hline \hline Pathogen (s) & \multicolumn{2}{c}{$\begin{array}{c}\text { Peromyscus } \\
\text { leucopus }\end{array}$} & \multicolumn{3}{c}{$\begin{array}{c}\text { Peromyscus } \\
\text { maniculatus }\end{array}$} \\
\hline Anaplasma phagocytophilum & $1 \%$ & $(1 / 94)$ & $0.6 \%$ & $(2 / 318)$ \\
Babesia microti & $15 \%$ & $(14 / 94)$ & $25 \%$ & $(80 / 318)$ \\
Borrelia burgdorferi & $19 \%$ & $(18 / 94)$ & $30 \%$ & $(94 / 318)$ \\
Borrelia mayonii & $0 \%$ & $(0 / 94)$ & $1.6 \%$ & $(5 / 318)$ \\
Borrelia miyamotoi & $1 \%$ & $(1 / 94)$ & $0.6 \%$ & $(2 / 318)$ \\
Ehrlichia muris eauclairensis & $0 \%$ & $(0 / 94)$ & $0.9 \%$ & $(3 / 318)$ \\
Bo. burgdorferi + Ba. microti & $8.5 \%$ & $(8 / 94)$ & $16 \%$ & $(51 / 318)$ \\
\hline
\end{tabular}

\section{Temporal detection of coinfection}

Twenty-four of the Bo. burgdorferi and $B a$. microti coinfected mice $(n=59)$ were captured in more than one month. At the first capture of individual animals, 42\% (10/24) were positive for both, $25 \%(6 / 24)$ were positive for $\mathrm{Ba}$. microti only, $4 \%(1 / 24)$ were positive for Bo. burgdorferi only, and neither pathogen was detected in $29 \%$ (7/24) of mice (Fig. 3). In 67\% (16/24) of mice, the first detection of either Bo. burgdorferi or $B a$. microti occurred simultaneously (mice were coinfected with both pathogens). Babesia microti also appeared to be more persistent in mice compared to Bo. burgdorferi; after first detection in an individual mouse, $B a$. microti DNA was detected in all subsequent captures. However, detection of Bo. burgdorferi failed in four mice that were previously identified as coinfected with both Ba. microti and Bo. burgdorferi. Within this subset of coinfected mice, we also detected A. phagocytophilum (1/24), Bo. mayonii (1/24), Bo. miyamotoi $(1 / 24)$, and E. m. eauclairensis $(1 / 24)$ (Fig. 3).

\section{Modified reservoir potential}

Modified reservoir potential ranged from zero to an estimated 8.3 larval ticks fed by $B o$. burgdorferi-infected P. maniculatus or P. leucopus per ha (Fig. 2c). While P. leucopus had higher larval infestations (Fig. 2b; Tables 1, 2), P. maniculatus had a higher infection prevalence (Table 4) and was the more abundant species (Fig. 2a) compared to $P$. leucopus. Overall, $P$. maniculatus had a higher modified reservoir potential than $P$. leucopus $(t=-3.6, \mathrm{df}=18, P<0.001)$. Additionally, $P$. maniculatus had a higher estimated modified

Table 5. Probability of infection of Borrelia burgdorferi in two Peromyscus species. Conditional average of four models predicting the likelihood of infection of Bo. burgdorferi in two Peromyscus species.

\begin{tabular}{lccccc}
\hline \hline Fixed effect & Level & Coefficient (SE) & $Z$ & $P$ & AOR (95\% CI) \\
\hline & (Intercept) & $-1.70(0.40)$ & 4.19 & $2.8 \mathrm{e}-05^{* * *}$ & $0.18(0.08-0.40)$ \\
Age & Immature & $-2.81(0.54)$ & 5.15 & $2 \mathrm{e}-07^{* * *}$ & $0.06(0.02-0.18)$ \\
Ba. microti & Positive & $1.56(0.29)$ & 5.42 & $1 \mathrm{e}-07^{* * *}$ & $4.75(2.70-8.34)$ \\
Species & P. maniculatus & $0.72(0.33)$ & 2.16 & $0.03^{*}$ & $2.06(1.07-3.98)$ \\
Sex & Male & $0.05(0.31)$ & 0.54 & 0.77 & $1.18(0.69-2.05)$ \\
Year & 2019 & $0.24(0.31)$ & 0.77 & 0.44 & $1.56(0.89-2.76)$ \\
\hline
\end{tabular}

Notes: Fixed effects included: Species $=$ Peromyscus species (two levels, $P$. leucopus is the reference). Year $=$ year sampled (two levels, 2018 is the reference). Sex: sex of mouse (female is the reference). Age = age of mouse (two levels, adult is the reference). Concurrent infection with Babeisa microti (two levels, positive is reference). Random effect included site. AOR, adjusted odds ratio; CI, confidence interval. Number of observations $=412$. We removed 11 individuals in which blood samples were not collected from the model analysis. * indicates parameter significantly affected the probability of infection at $P<0.05$. ${ }^{* * *}$ indicates parameter significantly affected the probability of infection at $P<0.001$. 


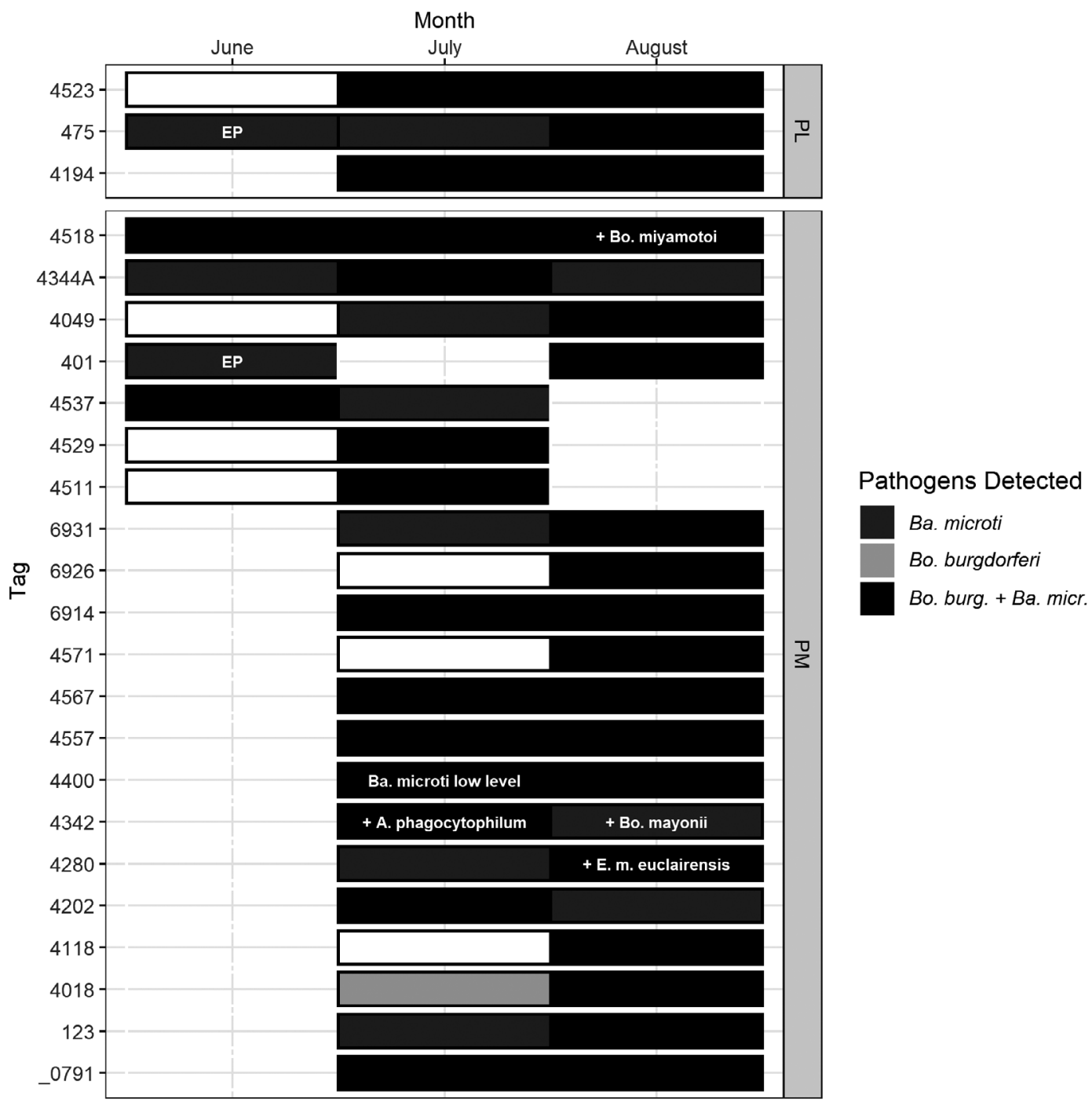

Fig. 3. Temporal detection of coinfection in Peromyscus leucopus and Peromyscus maniculatus (Taylor County WI, 2018-2019). Mice included in this subset were captured in at least two separate months and coinfected with Babesia microti and Borrelia burgdorferi in at least one of those months. Tag = the unique ear tag identifying each animal. PL and PM refer to P. leucopus and P. maniculatus, respectively. Black borders with white fill indicate that the animal was captured but no pathogens were detected. Ba. microti low level: pathogen concentration was below the limits of reliable detection based on RT-PCR crossing point values. Pathogens preceded by a plus sign (in example + Anaplasma phagocytophilium, + Borrelia mayonii, + Borrelia miyamotoi, and + Ehrlichia muris eauclairensis) annotates that these pathogens were concurrently detected. EP, indicates ear punch biopsy was used for testing $\mathrm{Ba}$. microti because blood sample a was not collected from this mouse. Ear punch samples were not included in pathogen analysis or modeling.

reservoir potential in 17 out the 19 monthly site visits, in which both species were captured (Fig. 2c). The two occasions when P. leucopus had a higher modified reservoir potential occurred at site 5 in July and August of 2019, when animal densities of the two species were very similar (Fig. 2b). The highest modified reservoir potentials for both species were recorded in July 2019. 


\section{DISCUSSION}

Our results show that $P$. maniculatus was responsible for infecting more larval ticks with Bo. burgdorferi at our field site (Taylor County, WI, 2018-2019) in comparison to P. leucopus. Peromyscus leucopus has sometimes been described as the "primary" or "most important" host of both larval I. scapularis and Bo. burgdorferi (Levine et al. 1985, Donahue et al. 1987, Ostfeld et al. 2006). However, Brisson et al. (2008) showed that shrews (Blarina and Sorex species) may be responsible for infecting more larval ticks than $P$. leucopus. Here, we demonstrate that P. leucopus may not always be the most important mouse host in terms of infecting larval ticks. While individual $P$. leucopus were more frequently infested with larval I. scapularis, P. maniculatus was the more abundant of the two species at our field site and, consequently, was feeding more larval ticks in total. Ultimately, the proportion of ticks that these two species are responsible for feeding and infecting is not only dependent on larval infestations but is also driven by the densities of each species.

In contrast to previous studies (Friedrich 2003, Bouchard et al. 2011, Larson et al. 2018), we found moderate evidence that $P$. maniculatus was more likely to be infected with Bo. burgdorferi. While this finding may be an artifact of the small number of $P$. leucopus represented in the study, both mice appear to be highly susceptible to $B o$. burgdorferi as well as numerous other tick-borne pathogens. In P. maniculatus, we detected not only Bo. burgdorferi and A. phagocytophilum but also Ba. microti, Bo. mayonii, and E. muris eauclairensis. According to Barbour (2017), these three pathogens had not been previously detected in P. maniculatus. With the exception of Ba. microti, in which transplacental transmission is possible (Tufts and Diuk-Wasser 2018), mice are thought to first acquire these infections through an infectious tick bite and P. leucopus is known to be a competent reservoir host for these pathogens. Assuming that $P$. maniculatus is a competent reservoir and can efficiently transmit these pathogens to ticks, this species should not be overlooked as a potential reservoir host for tick-borne pathogens in the Midwest.

In our study, we used modified reservoir potential to compare reservoir competency
(Hamer et al. 2012). This approach assumes that once infected, both mice species are equally efficient in transmitting pathogens to feeding larval ticks. This assumption could be tested by determining the proportion of ticks that acquire pathogens while feeding on an infected host and successfully molt into infected nymphs (Mather et al. 1989). Pathogen transmission efficiencies could be combined with our field-collected data to obtain more precise reservoir competence estimates (Mather et al. 1989). Further assessments of the reservoir competence of $P$. maniculatus are warranted to better understand their overall importance in tick-borne disease ecology.

Our results suggest that there is a positive association between Bo. burgdorferi and concurrent infection with $B a$. microti in both $P$. leucopus and P. maniculatus. This relationship was previously described in P. leucopus in the Northeast (Dunn et al. 2014, Hersh et al. 2014), and we show that $P$. maniculatus may also be an important source of coinfections in the Upper Midwest. Concurrent infection with Bo. burgdorferi and $B a$. microti is thought to increase severity and persistence of disease symptoms in humans (Krause et al. 1996). To better understand temporal patterns of pathogen coinfection, we examined infection statuses of coinfected mice over time. Within this subset of mice, we found that both pathogens were often first detected within the same month. In cases where pathogens were first detected singularly (only Bo. burgdorferi or $B a$. microti was detected), we found that infection with Ba. microti preceded Bo. burgdorferi more frequently than the reverse. Although transplacental transmission has been shown to promote earlier infection with $\mathrm{Ba}$. microti in mice, the first $B a$. microti detection for several mice in our study did not occur until subsequent captures, which suggests that at least some of the mice are first acquiring $B a$. microti from ticks in the environment rather than through transplacental infection (Tufts and Diuk-Wasser 2018). Further studies are needed to elucidate relationships between $B a$. microti and the acquisition and persistence of other tick-borne pathogens in Peromyscus hosts.

While P. maniculatus was the most abundant mouse at our field site, warming temperatures may favor $P$. leucopus in the future. Long-term observational studies have documented the 
northward range expansion of $P$. leucopus in the Midwest (Long 1996, Myers et al. 2005, 2009). Additionally, increases in the relative abundance of $P$. leucopus and even replacement of $P$. maniculatus by $P$. leucopus have been described in this region (Long 1996, Myers et al. 2005, 2009). It has been posited that shorter, milder winters may be a primary driver of range expansions and increases in relative abundance of $P$. leucopus (Long 1996, Myers et al. 2005, 2009, RoyDufresne et al. 2013). Based on our findings, tickborne disease risk may increase in areas where $P$. leucopus becomes the more dominant species. Compared to its congener, we found P. leucopus to be infested with more than twice as many larval I. scapularis at our study area. Similarly, Larson et al. (2018) found approximately three times more larval I. scapularis infesting P. leucopus compared to $P$. maniculatus. Therefore, shifts in favor of $P$. leucopus may result in more larval ticks being fed overall. To further illustrate this point, we considered a hypothetical scenario in which a population comprised of 10 P. maniculatus is completely replaced by $10 \mathrm{P}$. leucopus, assuming all other factors are held constant. Based on the modified reservoir potential values for July 2019 (the month of highest modified reservoir potential during our study), complete replacement of $P$. maniculatus with P. leucopus would result in 113\% increase in the number of ticks fed by mice and a $35 \%$ increase in the number of larval ticks infected with Bo. burgdorferi by mice.

Here, we established the first detection of three emerging tick-borne pathogens in P. maniculatus. Our results suggest that this mouse species is likely an important reservoir for tick-borne pathogens in the northernmost areas of the Midwest - in the areas where I. scapularis and the hallmark sign of Lyme disease were first reported and numerous tick-borne pathogens are endemic (Eisen et al. 2017). There is an urgent need to better understand differences in reservoir competency of these two species for the different tick-borne pathogens as the distributions and relative abundance of these mice species has been linked to climate (Myers et al. 2005, 2009, Roy-Dufresne et al. 2013). While future climate projections suggest the range of $P$. leucopus will expand poleward (Roy-Dufresne et al. 2013), it is not known if this species will also become the more dominant of the two forest-dwelling
Peromyscus species throughout the Midwest. This region contains the trailing edge of $P$. maniculatus (Fig. 1); thus, future studies should examine how the distribution and relative abundances of these species will respond to warming temperatures as well as the potential impacts on human tickborne disease risk.

\section{ACKNOWLEDGMENTS}

We thank the field crews for their hard work in rain and shine, John Orrock for sharing Sherman traps, and the wild rodents for their contribution to science. Additionally, we thank John Pauli for guidance on density estimates. Ryan Larson is a military service member, and this work was prepared as part of his official duties. Title 17 U.S.C. 105 provides that 'copyright protection under this title is not available for any work of the United States Government.' Title 17 U.S.C. 101 defines a U.S. Government work as work prepared by a military service member or employee of the U.S. Government as part of that person's official duties. The work was supported by the University of Wisconsin and by Cooperative Agreement Number U01CK000505, funded by the Centers for Disease Control and Prevention. Its contents are solely the responsibility of the authors and do not necessarily represent the official views or position of the Department of the Navy, Department of Defense, the Centers for Disease Control and Prevention, the Department of Health and Human Services, or the U.S. Government.

\section{Literature Cited}

Babady, N. E., L. M. Sloan, E. A. Vetter, R. Patel, and M. J. Binnicker. 2008. Percent positive rate of Lyme real-time polymerase chain reaction in blood, cerebrospinal fluid, synovial fluid, and tissue. Diagnostic Microbiology and Infectious Disease 62:464466.

Barbour, A. G. 2017. Infection resistance and tolerance in Peromyscus spp., natural reservoirs of microbes that are virulent for humans. Seminars in Cell \& Developmental Biology 61:115-122.

Bartoń, K. 2019. MuMIn: Multi-Model Inference. R Package Version 1.43.6. https://CRAN.R-project. org/package=MuMIn

Bates, D., M. Mächler, B. Bolker, and S. Walker. 2015. Fitting linear mixed-effects models using lme4. Journal of Statistical Software 67:1-48.

Bereczky, S., A. Mårtensson, J. P. Gil, and A. Färnert. 2005. Short report: rapid DNA extraction from archive blood spots on filter paper for genotyping of Plasmodium falciparum. American Society of Tropical Medicine and Hygiene 72:249-251. 
Bouchard, C., G. Beauchamp, S. Nguon, L. Trudel, F. Milord, L. R. Lindsay, D. Bélanger, and N. H. Ogden. 2011. Associations between Ixodes scapularis ticks and small mammal hosts in a newly endemic zone in southeastern Canada: implications for Borrelia burgdorferi transmission. Ticks and Tick-borne Diseases 2:183-190.

Brisson, D., D. E. Dykhuizen, and R. S. Ostfeld. 2008. Conspicuous impacts of inconspicuous hosts on the Lyme disease epidemic. Proceeding of the Royal Society B 275:227-235.

Burgess, E. C., T. E. Amundson, J. P. Davis, R. A. Kaslow, and R. Edelman. 1986. Experimental inoculation of Peromyscus spp. with Borrelia burgdorferi: evidence of contact transmission. American Journal of Tropical Medicine and Hygiene 35:355-359.

Burnham, K. P., and D. R. Anderson. 2002. Model selection and multimodel inference: a practical information-theoretic approach. Second edition. Springer, New York, New York, USA.

Castillo, C. G., M. E. Eremeeva, S. M. Paskewitz, L. M. Sloan, X. Lee, W. E. Irwin, S. Tonsberg, and B. S. Pritt. 2015. Detection of human pathogenic Ehrlichia muris-like agent in Peromyscus leucopus. Ticks and Tick-borne Diseases 6:155-157.

Cayol, C., A. Jääskeläinen, E. Koskela, S. Kyröläinen, T. Mappes, A. Siukkola, and E. R. Kallio. 2018. Sympatric Ixodes-tick species: pattern of distribution and pathogen transmission within wild rodent populations. Scientific Reports 8:16660.

Clifford, C. M., G. Anastos, and A. Van der BorghtElbl. 1961. The larval ixodid ticks of the eastern United States (Acarina-Ixodidae). Miscellaneous Publications of the Entomological Society of America 2:215-244.

Deardorff, E. R., R. A. Nofchissey, J. A. Cook, A. G. Hope, A. Tsvetkova, S. L. Talbot, and G. D. Ebel. 2013. Powassan virus in mammals, Alaska and New Mexico, USA, and Russia, 2004-2007. Emerging Infectious Diseases 19:2012-2016.

Donahue, J. G., J. Piesman, and A. Spielman. 1987. Reservoir competence of white-footed mice for Lyme disease spirochetes. American Journal of Tropical Medicine and Hygiene 36:92-96.

Drickamer, L. C., and B. M. Vestal. 1973. Patterns of reproduction in a laboratory colony of Peromyscus. Journal of Mammalogy 54:523-528.

Dunn, J. M., et al. 2014. Borrelia burgdorferi promotes the establishment of Babesia microti in the northeastern United States. PLOS ONE 9:e115494.

Durden, L. A., and J. E. Keirans. 1996. Nymphs of the genus Ixodes (Acari: Ixodidae) of the United States: taxonomy, identification key, distribution, hosts, and medical/veterinary importance. Thomas Say
Publications in Entomology, Entomological Society of America, Lanham, Maryland, USA.

Eisen, R. J., K. J. Kugeler, L. Eisen, C. B. Beard, and C. D. Paddock. 2017. Tick-borne zoonoses in the United States : persistent and emerging threats to human health. ILAR Journal 58:319-335.

Friedrich, T. J. 2003. Ecology of sympatric species of Peromyscus as hosts for Ixodes scapularis and Borrelia burgdorferi in northern Michigan forests. Dissertation. University of Michigan, Ann Arbor, Michigan, USA.

Hamer, S. A., G. J. Hickling, J. L. Sidge, E. D. Walker, and J. I. Tsao. 2012. Synchronous phenology of juvenile, Ixodes scapularis, vertebrate host relationships, and associated patterns of Borrelia burgdorferi ribotypes in the midwestern United States. Ticks and Tick-borne Diseases 3:65-74.

Hersh, M. H., R. S. Ostfeld, D. J. McHenry, M. Tibbetts, J. L. Brunner, M. E. Killilea, K. LoGiudice, K. A. Schmidt, and F. Keesing. 2014. Co-infection of blacklegged ticks with Babesia microti and Borrelia burgdorferi is higher than expected and acquired from small mammal hosts. PLOS ONE 9:e99348.

Huggins, R. M. 1989. On the statistical analysis of capture experiments. Biometrika 76:133-140.

Jannett, F. J., M. R. Broschart, L. H. Grim, and J. P. Schaberl. 2007. Northerly range extensions of mammalian species in Minnesota. American Midland Naturalist 158:168-176.

Johnson, R. C., C. Kodner, J. Jarnefeld, D. K. Eck, and Y. Xu. 2011. Agents of human anaplasmosis and Lyme disease at Camp Ripley, Minnesota. VectorBorne and Zoonotic Diseases 11:1529-1534.

Johnson, T. L., et al. 2017. Isolation of the Lyme disease spirochete Borrelia mayonii from naturally infected rodents in Minnesota. Journal of Medical Entomology 54:1088-1092.

Kaizer, A. M., S. A. Foré, H.-J. Kim, and E. C. York. 2015. Modeling the biotic and abiotic factors that describe the number of active off-host Amblyomma americanum larvae. Journal of Vector Ecology 40:110.

Krause, P. J., et al. 1996. Concurrent Lyme disease and babesiosis: evidence for increased severity and duration of illness. Journal of the American Medical Association 275:1657-1660.

Laake, J. L. 2013. RMark: an R interface for analysis of capture-recapture data with MARK. AFSC Processed Report 2013-01. Alaska Fisheries Science Center, National Marine Fisheries Service, Seattle, Washington, USA.

Larson, S. R., X. Lee, and S. M. Paskewitz. 2018. Prevalence of tick-borne pathogens in two species of Peromyscus mice common in northern Wisconsin. Journal of Medical Entomology 55:1002-1010. 
Levine, J. F., M. L. Wilson, and A. Spielman. 1985. Mice as reservoirs of the Lyme disease spirochete. American Journal of Tropical Medicine and Hygiene 34:355-360.

Long, C. A. 1996. Ecological replacement of the deer mouse, Peromyscus maniculatus, by the whitefooted mouse, P. leucopus, in the Great Lakes Region. Canadian Journal of Zoology 110:271-277.

Mather, T. N., M. L. Wilson, S. I. Moore, J. M. C. Ribeiro, and A. Spielman. 1989. Comparing the relative potential of rodents as reservoirs of the Lyme disease spirochete (Borrelia burgdorferi). American Journal of Epidemiology 130:143-150.

Myers, P., B. L. Lundrigan, S. M. G. Hoffman, A. P. Haraminac, and S. H. Seto. 2009. Climate-induced changes in the small mammal communities of the Northern Great Lakes Region. Global Change Biology 15:1434-1454.

Myers, P., B. L. Lundrigan, and R. Vande Kopple. 2005. Climate change and the distribution of Peromyscus in Michigan: Is global warming already having an impact? University of California Publications in Zoology 133:101-125.

Ostfeld, R. S., C. D. Canham, K. Oggenfuss, R. J. Winchcombe, and F. Keesing. 2006. Climate, deer, rodents, and acorns as determinants of variation in Lyme-disease risk. PLOS Biology 4:e145.

Parmenter, R. R., et al. 2003. Small-mammal density estimation: a field comparison of grid-based vs. web-based density estimators. Ecological Monographs 73:1-26.

Peromyscus maniculatus subsp. gracilis in GBIF Secretariat. 2017. GBIF Backbone Taxonomy. Checklist dataset https://doi.org/10.15468/39omei, accessed via GBIF.org.

R Development Core Team. 2018. R: a language and environment for statistical computing. R Foundation for Statistical Computing, Vienna, Austria.

Rand, P. W., E. H. Lacombe, R. P. Smith, S. M. Rich, W. C. Kilpatrick, C. A. Dragoni, and D. Caporale. 1993. Competence of Peromyscus maniculatus (Rodentia: Cricetidae) as a reservoir host for Borrelia burgdorferi (Spirochaetares: Spirochaetaceae) in the wild. Journal of Medical Entomology 30:614-618.

Roy-Dufresne, E., T. Logan, J. A. Simon, G. L. Chmura, and V. Millien. 2013. Poleward expansion of the white-footed mouse (Peromyscus leucopus) under climate change: implications for the spread of Lyme disease. PLOS ONE 8:e80724.

Ruebush, T. K., D. D. Juranek, A. Spielman, J. Piesman, and G. R. Healy. 1981. Epidemiology of human babesiosis on Nantucket Island. American Journal of Tropical Medicine and Hygiene 30:937-941

Sambado, S., J. Salomon, A. Crews, and A. Swei. 2020. Mixed transmission modes promote persistence of an emerging tick-borne pathogen. Ecosphere 11: e03171.

Schwemm, C. A., C. A. Drost, J. L. Orrock, T. J. Coonan, and T. R. Stanley. 2018. Comparison of estimators for monitoring long-term population trends in deer mice, Peromyscus maniculatus, on the California Channel Islands. Western North American Naturalist 78:496-509.

Scoles, G. A., M. Papero, L. Beati, and D. Fish. 2001. A relapsing fever group spirochete transmitted by Ixodes scapularis ticks. Vector-Borne and Zoonotic Diseases 1:21-34.

Scrimenti, R. J. 1970. Eythema chonicum migrans. Archives of Dermatology 102:104-105.

Simon, J. A., et al. 2014. Climate change and habitat fragmentation drive the occurrence of Borrelia burgdorferi, the agent of Lyme disease, at the northeastern limit of its distribution. Evolutionary Applications 7:750-764.

Stauffer, M. T., J. Mandli, B. S. Pritt, W. Stauffer, L. M. Sloan, T. Zembsch, X. Lee, and S. M. Paskewitz. 2020. Detection of zoonotic human pathogens from Ixodes scapularis in Wisconsin. Journal of Vector Ecology 45:147-149.

Stephens, R. B., and E. M. Anderson. 2014. Habitat associations and assemblages of small mammals in natural plant communities of Wisconsin. Journal of Mammalogy 95:404-420.

Telford, S. R., J. E. Dawson, P. Katavolos, C. K. Warner, C. P. Kolbert, and D. H. Persing. 1996. Perpetuation of the agent of human granulocytic ehrlichiosis in a deer tick-rodent cycle. Proceedings of the National Academy of Sciences 93: 62096214.

Tessier, N., S. Noël, and F.-J. Lapointe. 2004. A new method to discriminate the deer mouse (Peromyscus maniculatus) from the white-footed mouse (Peromyscus leucopus) using species-specific primers in multiplex PCR. Canadian Journal of Zoology 82:1832-1835.

Tufts, D. M., and M. A. Diuk-Wasser. 2018. Transplacental transmission of tick-borne Babesia microti in its natural host Peromyscus leucopus. Parasites and Vectors 11:286.

VanAcker, M. C., E. A. H. Little, G. Molaei, W. I. Bajwa, and M. A. Diuk-Wasser. 2019. Enhancement of risk for Lyme disease by landscape connectivity, New York, New York, USA. Emerging Infectious Diseases 25:1136-1143.

Wickham, H. 2016. ggplot2: elegant graphics for data analysis. Second edition. Springer, New York, New York, USA.

Wolff, J. O. 1996. Coexistence of white-footed mice and deer mice may be mediated by fluctuating environmental conditions. Oecologia 108:529-533. 


\section{DATA AVAILABILITY}

Data are available from the Center for Open Science: https://osf.io/xmtpe/?view_only=242ac04e5db44feb90361 500f15046b8

\section{SUPPORTING INFORMATION}

Additional Supporting Information may be found online at: http://onlinelibrary.wiley.com/doi/10.1002/ecs2. $3831 /$ full 